\title{
Association between resilience and posttraumatic stress disorder among Brazilian victims of urban violence: a cross-sectional case-control study
}

\author{
Associação entre resiliência e transtorno de estresse pós-traumático em \\ vítimas de violência urbana no Brasil: estudo transversal de caso e controle
}

\author{
Stefania Pigatto Teche, ${ }^{1,2}$ Alcina Juliana Soares Barros, ${ }^{1}$ Regis Goulart Rosa, ${ }^{3}$ Luciano Pinto Guimarães, ${ }^{2}$ \\ Kariny Larissa Cordini, ${ }^{1}$ Julia Domingues Goi, ${ }^{1}$ Simone Hauck, ${ }^{1,2}$ Lucia Helena Freitas ${ }^{1,2}$
}

\begin{abstract}
Introduction: This study investigated the association between resilience and posttraumatic stress disorder (PTSD) among Brazilian victims of urban violence. It also compared defense mechanisms, parental bonding, and childhood trauma between those who developed PTSD and those who did not.

Methods: This cross-sectional case-control study included 66 adult subjects exposed to recent urban violence in southern Brazil - 33 with PTSD and 33 healthy controls matched by sex and age - who were administered the Resilience Scale, Defense Style Questionnaire, Parental Bonding Instrument, and Childhood Trauma Questionnaire. The statistical tests used were the McNemar test for categorical variables, the Wilcoxon signedrank test for continuous asymmetric variables, and the paired Student $t$-test for continuous symmetric variables.

Results: The PTSD group showed lower total Resilience Scale scores compared with controls $(128.4 \pm 20.7$ vs. $145.8 \pm 13.1$, respectively; $p=0.01$ ), along with a lower ability to solve situations and lower personal values that give meaning to life $(p=0.019)$. They also had lower rates of mature defense mechanisms $(p<0.001)$ and higher rates of emotional ( $p=$ 0.001 ) and physical ( $p=0.003$ ) abuse during childhood.

Conclusion: Lower levels of resilience, especially the ability to solve situations and having personal values that give meaning to life, immature defense mechanisms, and emotional and physical abuse in childhood are associated with PTSD in adult Brazilian victims of urban violence.
\end{abstract}

Keywords: Resilience, stress disorders, urban violence, defense mechanisms, parental bonding, psychological trauma.

\section{Resumo}

Introdução: Este estudo investigou a associação entre resiliência e transtorno de estresse pós-traumático (TEPT) entre vítimas brasileiras de violência urbana. Comparou os mecanismos de defesa, vínculos parentais e trauma infantil entre vítimas que desenvolveram TEPT e vítimas que não desenvolveram o transtorno.

Métodos: Estudo de caso-controle transversal que incluiu 66 sujeitos adultos expostos à violência urbana no sul do Brasil. Foram avaliados 33 pacientes com TEPT e 33 controles saudáveis pareados por sexo e idade, que responderam a Escala de Resiliência, Questionário do Estilo Defensivo, Instrumento de Ligação Parental e Questionário sobre Traumas Infantis. Os testes estatísticos utilizados foram o teste de McNemar para variáveis categóricas, teste Wilcoxon para variáveis assimétricas contínuas e teste $t$ de Student pareado para variáveis simétricas contínuas. Resultados: $\mathrm{O}$ grupo que desenvolveu TEPT apresentou escores totais da Escala de Resiliência mais baixos em relação aos controles $(128,4 \pm 20,7$ versus $145,8 \pm 13,1$, respectivamente; $p$ $=0,01)$, juntamente com uma menor capacidade em resolver situações e menores índices de valores pessoais que dão sentido à vida $(p=0,019)$. Também apresentaram taxas mais baixas de uso de mecanismos de defesas maduros $(p<0,001)$ e maiores taxas de abuso emocional $(p=0,001)$ e físico $(p=0,003)$ durante a infância.

Conclusão: Níveis mais baixos de resiliência, especialmente a capacidade de resolver situações e ter valores pessoais que dão sentido à vida, mecanismos imaturos de defesa e abuso físico e emocional na infância estão associados ao TEPT em adultos vítimas de violência urbana no Brasil.

Descritores: Resiliência, transtorno de estresse, violência urbana, mecanismos de defesa, vínculos parentais, trauma psicológico.

\footnotetext{
${ }_{1}^{1}$ Programa de Pós-Graduação em Psiquiatria e Ciências do Comportamento, Universidade Federal do Rio Grande do Sul (UFRGS), Porto Alegre, RS, Brazil. 2 Hospital de Clínicas de Porto Alegre (HCPA), Porto Alegre, RS, Brazil. ${ }^{3}$ Programa de Pós-Graduação em Ciências Médicas, UFRGS, Porto Alegre, RS, Brazil. Submitted Oct 11 2016, accepted for publication Apr 102017.

Suggested citation: Teche SP, Barros AJS, Rosa RG, Guimarães LP, Cordini KL, Goi JD, et al. Association between resilience and posttraumatic stress disorder among Brazilian victims of urban violence: a cross-sectional case-control study. Trends Psychiatry Psychother. 2017;39(2):116-123. http://dx.doi.org/10.1590/22376089-2016-0070
} 


\section{Introduction}

The Brazilian urban population is highly exposed to urban violence. ${ }^{1}$ In this context, when an individual is victimized by a serious act of urban violence, such as rape, kidnapping, or assault, he or she is exposed to the risk of developing various mental health disorders, including posttraumatic stress disorder (PTSD). ${ }^{2}$ In developed countries, the lifetime prevalence of traumatic events is around $60 \%$; in comparison, epidemiological data has shown that $80 \%$ of the Brazilian population was exposed to urban violence at least once. Conversely, even though Brazilians are highly exposed to urban violent events, around $90 \%$ of them do not develop PTSD. According to one study, $10.2 \%$ of the exposed population in São Paulo and $8.7 \%$ in Rio de Janeiro developed PTSD, which, therefore, represents an important public health issue. ${ }^{3}$

One of the factors that could be involved in the protection of an individual's mental health is resilience, but there is little evidence on any association between resilience and the victims of urban violence who do not develop PTSD. Resilience is the process of negotiating, handling, and adapting to a highly stressful or traumatic event. ${ }^{4}$ Resilience to stress is multifactorial and includes the individual's psychological and neurobiological profile, as well as environmental characteristics such as a personal history of trauma or a lack of social support. 5,6 Psychosocial factors correlated with resilience have been investigated in several studies. These include positive emotions and optimism, actively facing fear, cognitive flexibility, a moral guide based on values, spirituality, and social support.7-9 Improving these psychosocial factors may therefore help ameliorate the negative effects of violence on mental health. ${ }^{10}$ Regarding the multifactorial nature of resilience, an individual's characteristic style of defense mechanism, parental bonding, and childhood trauma could be important aspects of that individual's psychological and neurobiological profile and may therefore be associated with a greater or lesser degree of resilience. Mature defense mechanisms and the absence of early-life stress may be associated with greater resilience.

Similarly, data are lacking about other characteristics that may be associated with protection against PTSD, such as a mature defense style, the absence of early-life trauma, and parental bonding of good quality. Mature defense mechanisms protect the individual in stressful situations; conversely, immature defense mechanisms, such as isolation, undoing, projection, splitting, and rationalization are used to a greater extent by patients who develop PTSD symptoms. ${ }^{11-13}$ The absence of early life stress can be considered a protective factor in the context of urban violence, ${ }^{14-16}$ but sexual abuse in childhood is associated with a higher risk of developing PTSD in adult life. ${ }^{17-19}$ Another possible early life stress is a dysfunctional parental bond. ${ }^{20}$ The perception of having a non-controlling mother and a caring father during childhood and adolescence was protective against the development of PTSD following exposure to severe urban violence in adulthood. ${ }^{21}$ In addition, physical and emotional neglect during childhood are associated with the extension of current posttraumatic and general psychological distress. ${ }^{22}$

We, therefore, conducted this study to investigate the association between resilience and PTSD among Brazilian victims of urban violence. We also aim to identify differences in possible determinants of resilience, such as defense mechanisms, parental bonding, and childhood trauma, between the victims of urban violence who developed PTSD and those who did not. We hypothesized that individuals who did not develop PTSD may display higher resilience characteristics, a mature defense style, absence of early-life trauma, and parental bonding of good quality.

\section{Methods}

\section{Study design, setting, and subjects}

This cross-sectional case-control study was conducted between October 2007 and September 2009 with 66 adults ( 33 cases and 33 controls) living in the urban area of Porto Alegre, state of Rio Grande do Sul, southern Brazil. Cases were sampled by convenience among patients seeking assistance at Net-Trauma, an outpatient referral psychiatry program at Hospital de Clínicas de Porto Alegre (HCPA) that provides psychiatric evaluation, diagnosis, and treatment for patients who were exposed to traumatic events. This program receives an average of 48 patients per year. This study was approved by the institutional ethics committee of HCPA (protocol no. 10-0450). Written informed consent was obtained from all participants prior to enrollment in the study.

The inclusion criteria for cases were referral to Net-Trauma and recent exposure to a traumatic urban violence event. Exclusion criteria for cases were: age $<18$ years, absence of PTSD related to the patient's recent exposure to urban traumatic violence, refusal to provide informed consent, and failure to attend the first research evaluation. PTSD was established in accordance with criteria from the Diagnostic and Statistical Manual of Mental Disorders, 4th edition (DSM-IV), using the Mini International Neuropsychiatric Interview (MINI). ${ }^{23}$ 
Controls were selected by convenience among relatives of inpatients admitted for non-psychiatric clinical or surgical treatment at the same hospital (HCPA) - the aim was to include a control group with the same sociodemographic background as that of the cases. All relatives of patients hospitalized in general and surgical medical units were interviewed about exposure to a traumatic event. Individuals who suffered a traumatic urban violence event according to criterion A of the Diagnostic and Statistical Manual of Mental Disorders, 4th edition, Text Revision (DSM-IV-TR) ${ }^{24}$ but without a PTSD outcome were selected. Exclusion criteria for controls were a history of mental illness, use of psychopharmacological drugs, current psychiatric symptoms (as evaluated by a score $\geq 7$ in the SelfReporting Questionnaire [SRQ] screening tool ${ }^{25}$ ), and psychiatric disorders (as assessed by MINI). Cases and controls were matched one-to-one by age and sex.

\section{Measurements}

PTSD symptoms and severity were scored using the Davidson Trauma Scale, ${ }^{26}$ which has a subscore Cronbach alpha of 0.915 . Four instruments were applied to evaluate psychological and environmental factors associated with trauma and resilience. The Resilience Scale ${ }^{27}$ and the Defense Style Questionnaire (DSQ) ${ }^{28}$ were chosen to evaluate behavioral characteristics related to coping with stressors. The Childhood Trauma Questionnaire (CTQ) ${ }^{29}$ and the Parental Bonding Instrument (PBI) ${ }^{30}$ were used to assess exposure to early-life stress.
The Resilience Scale was adapted for use in Brazil by Pesce et al. ${ }^{31}$ The scale evaluates positive psychosocial adaptation in face of important life events. It comprises 25 Likert-type items ranging from 1 (totally disagree) to 7 (totally agree) and subdivided into three factors: Factor I, ability to solve situations and personal values that give meaning to life (calculated from 14 items and defined as the accomplishment of actions related to energy, persistence, discipline, conception of values that carry out actions aimed at giving meaning to life such as friendship, personal fulfillment, satisfaction and meaning of life); Factor II, independence and determination (calculated from 6 items and defined as the ability to solve difficult situations alone, deal with various situations at the same time, accept adversities and accept situations that cannot be changed); and Factor III, self-confidence and adaptation (calculated from 5 items and defined as the belief that the person can solve their problems, carry out actions against their will keeping interest in things that they consider important).

The DSQ was adapted for use in Brazil by Blaya, et al. It is used to identify the characteristic style of how people deal with conflict based on the idea that people can accurately comment on their behavior. Individual defense scores are calculated by obtaining the mean of two items for each given defense mechanism, and factor scores are calculated by using the mean scores of the defenses belonging to each factor. Each item is evaluated using a scale from 1 to 9 , where 1 indicates completely disagree and 9 indicates fully agree. The results of the DSQ can provide scores for 20 individual defenses and for three factors: mature, neurotic, and immature. ${ }^{32}$
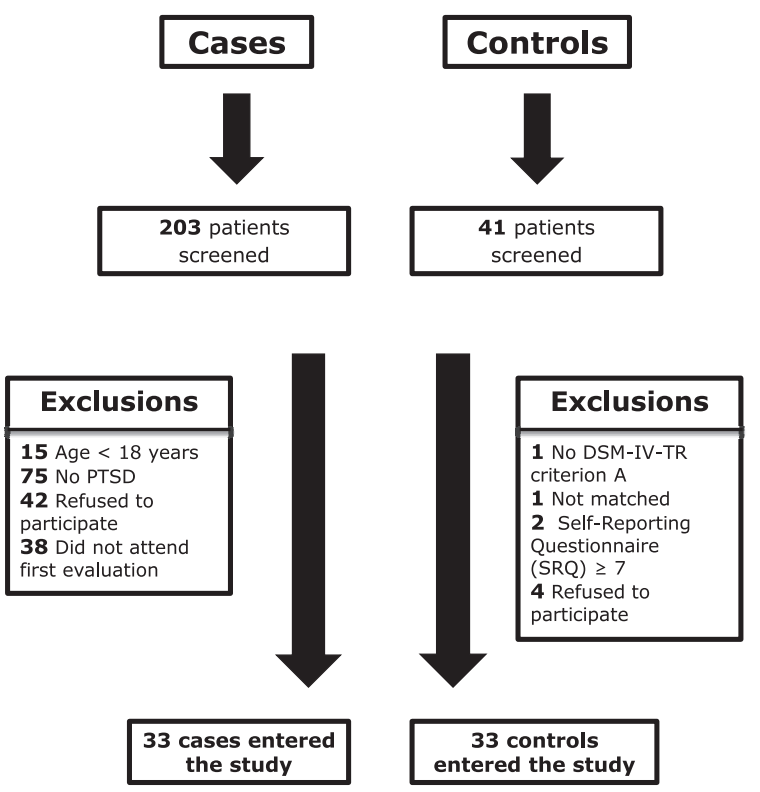

Figure 1 - Flow chart showing inclusion and exclusion of cases and controls. 
The $\mathrm{CTQ}^{33}$ investigates five traumatic components: emotional abuse, physical abuse, sexual abuse, emotional neglect, and physical neglect. It is an instrument for adolescents and adults where the responder rates the frequency of 28 assertions related to situations occurred in childhood using a five-point Likert scale. The PBI was designed to measure parental styles as perceived by the respondents during their first 16 years. It is a Likert-type scale (ranging from 0 to 3 ) consisting of 25 items related to father and mother. This scale was originally devised to measure two factors (according to Parker et al., in 197930): care (affection and warmth vs. coldness and rejection) and protection (control, intrusion vs. encouragement of autonomy). Later, Kendler ${ }^{34}$ proposed an analysis with three factors of the PBI: care, protectiveness and authoritarianism. This model seems to be relatively invariant regarding gender and age. The results of the PBI can be based on Parker (care and protection) or on Kendler (care, protectiveness and authoritarianism), according to the Brazilian version. ${ }^{35,36}$

\section{Statistical analysis}

Continuous variables are presented as means and standard deviations or medians and ranges (1st and 3rd quartiles); categorical variables are presented as percentages. Demographic and clinical characteristics were compared between the two study groups using the McNemar test for categorical variables, the Wilcoxon signed-rank test for continuous asymmetric variables, and the paired Student $t$-test for continuous symmetric variables. A significance level of 0.05 was adopted for all statistical comparisons. The analysis was performed using the Statistical Package for the Social Sciences (SPSS) version 18.0.

\section{Results}

\section{Subject characteristics}

The clinical and demographic characteristics of the sample are presented in Table 1 . School years showed a normal distribution and the paired $t$-test found no significant differences between cases and controls. Even though this variable was not used for case-control pairing, this result confirms that both groups were similar in terms of social and demographic characteristics.

To evaluate differences in exposure load between the PTSD and resilient groups, we ranked traumatic events according their individual conditional risk for developing PTSD. This rank was based on indexes calculated by Kessler et al. using data from WHO World Mental Health Surveys. ${ }^{37}$ Traumatic events were ranked in descending order of severity and the participants described a total of 10 types, as follows: rape, assault by their partner, kidnapping, sexual assault, gang stalking, urban violence-related death of a loved one, life-threatening accident, life-threatening motor vehicle accident, assault by a stranger, and being mugged with a weapon. There were no differences between the groups

Table 1 - Clinical and demographic data of patients with posttraumatic stress disorder and resilient controls

\begin{tabular}{|c|c|c|c|}
\hline & Cases $(n=33)$ & Controls $(n=33)$ & $\mathbf{p}$ \\
\hline \multicolumn{4}{|l|}{ Gender* } \\
\hline Male & $5(15.2)$ & $5(15.2)$ & $>0.999$ \\
\hline Female & $28(84.8)$ & $28(84.8)$ & \\
\hline Age $\left(\right.$ years) ${ }^{+}$ & $43.12(9.7)$ & $43.21(9.4)$ & 0.662 \\
\hline Education $\left(\right.$ years) $^{+}$ & $9.36(2.7)$ & $10.24(3.9)$ & 0.337 \\
\hline Ethnicity (Caucasian)* & $26(78.8)$ & $31(93.9)$ & 0.247 \\
\hline \multicolumn{4}{|l|}{ Marital status* } \\
\hline Single & $6(18.2)$ & $3(9.1)$ & 0.371 \\
\hline Married & $18(54.5)$ & $25(75.8)$ & \\
\hline Divorced & $7(21.2)$ & $4(12.1)$ & \\
\hline Widowed & $2(6.1)$ & $1(3.0)$ & \\
\hline \multicolumn{4}{|c|}{ Previous history of psychiatric illness* } \\
\hline No & $27(81.8)$ & $33(100)$ & - \\
\hline Yes & $6(18.2)$ & - & \\
\hline \multicolumn{4}{|c|}{ Previous history of trauma* } \\
\hline No & $17(51.5)$ & $17(51.5)$ & $>0.999$ \\
\hline Yes & $16(48.5)$ & $16(48.5)$ & \\
\hline
\end{tabular}

* Variable presented as $\mathrm{n}(\%)$ and compared using the McNemar test.

+ Variable presented as mean (standard deviation) and compared using the paired $t$ test. 
in terms of exposure to traumatic events according to their specific conditional risk for developing PTSD.

The time elapsed from the day of trauma until administration of the questionnaire was analyzed as a continuous variable in months and showed no significant difference between the cases and controls considering median and range (24 [3.0-96.0] vs. 48 [24.0-108.0] months; $p=0.228$ ).

\section{Intergroup comparison}

PTSD cases showed lower total scores in the

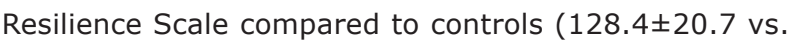
$145.8 \pm 13.1 ; \mathrm{p}=0.01)$.

Table 2 shows the comparison of results obtained by the instruments in PTSD cases and resilient controls. The Resilience Scale score was calculated based on orthogonal rotation, producing three factors: Factor I, Factor II, and Factor III, already described above. A significant difference was found in Resilience Scale Factor I, showing that controls had a greater ability to solve situations and had more personal values that give meaning to life (control group 5.9 vs. PTSD group 5.2; $\mathrm{p}=0.019$ ).

Parental style perception, as measured by PBI, did not differ between cases and controls. There was a tendency in the resilient group to perceive better care (affection and warmth) of their caregivers, but it was not statistically significant (Table 2). PTSD cases suffered greater physical and emotional abuse when compared to resilient controls. The resilient group used more mature defense mechanisms to deal with conflict than the PTSD group. Moreover, the resilient group used less immature defense mechanisms.

\section{Discussion}

We found that the capacity to solve situations and personal values that give meaning to life were higher in the individuals who suffered a traumatic urban violence event but did not develop PTSD. This result is consistent with the primary hypothesis that individuals who experience trauma and do not develop PTSD have behavioral characteristics that enable better adaptation in stressful situations. It also partially corroborates previous findings, because the difference between groups was found in only one resilience subscale, which identified that actively facing problems and having moral characteristics and values that guide the behavior are psychosocial factors that predispose to resilience. ${ }^{38,39}$ Furthermore, our findings are consistent with those of Hjemdal et al., ${ }^{40}$ who presented personal

Table 2 - Comparison of variables measured by instruments in cases of posttraumatic stress disorder and resilient controls

\begin{tabular}{|c|c|c|c|}
\hline & Cases $(n=33$ or $20 *)$ & Controls $(n=33$ or $20 *)$ & $\mathbf{p}$ \\
\hline \multicolumn{4}{|l|}{ Resilience $^{+}$} \\
\hline Factor I & $5.2(4.3-5.9)$ & $5.9(5.5-6.4)$ & 0.019 \\
\hline Factor II & $5.8(4.4-6.7)$ & $6.1(5.5-6.9)$ & 0.176 \\
\hline Factor III & $5.3(4.0-5.5)$ & $5.9(4.9-6.5)$ & 0.138 \\
\hline \multicolumn{4}{|l|}{$\mathrm{PBI}^{+}$} \\
\hline Parker care & $36.0(22.0-51.0)$ & $47.5(38.2-60.0)$ & 0.07 \\
\hline Parker protection & $30.5(14.5-44.5)$ & $26.5(17.5-43.5)$ & 0.89 \\
\hline Kendler care & $21.0(12.2-28.7)$ & $27.0(21.2-33.7)$ & 0.06 \\
\hline Kendler protectiveness & $6.5(3.0-15.0)$ & $10.5(5.0-14.0)$ & 0.64 \\
\hline Kendler authoritarianism & $10.5(6.5-15.0)$ & $10.5(5.2-16.0)$ & 0.71 \\
\hline \multicolumn{4}{|l|}{$\mathrm{CTQ}^{+}$} \\
\hline Emotional abuse & $13(6.5-16.0)$ & $7(5.0-9.0)$ & 0.001 \\
\hline Physical abuse & $8(6.0-13.5)$ & $6(5.0-7.5)$ & 0.003 \\
\hline Sexual abuse & $5(5.0-8.5)$ & $5(5.0-5.0)$ & 0.074 \\
\hline Emotional neglect & $11(6.5-20.5)$ & $17(9.5-23.0)$ & 0.092 \\
\hline Physical neglect & $10(7.0-13.0)$ & $13(7.5-14.5)$ & 0.271 \\
\hline \multicolumn{4}{|l|}{$\mathrm{DSQ}^{\ddagger}$} \\
\hline Mature & $5.3(1.61)$ & $8.1(1.73)$ & $<0.001$ \\
\hline Neurotic & $4.8(1.51)$ & $5.1(1.75)$ & 0.419 \\
\hline Immature & $3.9(1.02)$ & $3.2(1.28)$ & 0.016 \\
\hline
\end{tabular}

Bold font indicates statistical significance.

$\mathrm{CTQ}=$ Childhood Trauma Questionnaire; $\mathrm{DSQ}=$ Defense Style Questionnaire; PBI = Parental Bonding Instrument

$* \mathrm{n}=20$ occurred only with PBI.

+ Variable presented as median (1st and 3rd quartiles) and compared using Wilcoxon's test.

* Variable presented as mean (standard deviation) and compared using the paired $t$ test. 
resources, impulse control, problem solving abilities, certain qualities in the family, and social support as characteristics of resilient individuals.

Previous researches confirm that a bond of care and protection with parents is supposed to facilitate the development of mature defense mechanisms, which will be necessary to cope with traumatic situations. In our research, the tendency found was similar to that reported in previous studies involving violence victims and PTSD. The perception of low control (incentive of autonomy) and high parental care (affective bonding) in childhood and the quality of affective bonding were predictive of resilience and of a lower risk of PTSD in adulthood. ${ }^{41-44}$

Furthermore, early history of physical or emotional abuse was more prevalent in the PTSD patients, confirming our primary hypothesis and increasing our confidence in the results derived from other studies in that individuals who experience childhood maltreatment are more vulnerable to PTSD symptoms later in life. $7,42,45-47$

The present study found mature defenses to be expressed to a greater level in the control group, whereas immature defenses predominated in PTSD patients, corroborating the initial hypothesis that defense mechanisms are behavioral characteristics related to the capacity for adaptation. This result also agrees with the report of Simeon et al., which considered mature defenses to be a well-validated indicator of resilience. ${ }^{48}$ Other studies have also identified immature defense mechanisms as predictors of PTSD, including rationalization, splitting, projection, undoing, and isolation. ${ }^{11,13}$

The strength of the present study lies in the selection of our control group; most studies on PTSD have not included a control group of individuals who underwent traumatic events similar to those of the PTSD group. The individuals in the control group were considered in the present study to be "resilient" because they did not develop PTSD following exposure to an urban violence traumatic event. The control group was paired by sex and age with the PTSD group and included individuals who came from the same sociodemographic background as the PTSD group, strengthening the external validity of this study. Furthermore, having a majority of females in our sample (around $85 \%$ ) is consistent with other PTSD studies. Women have a three times higher overall conditional risk for developing PTSD than men, with a higher conditional risk for most types of traumatic events. ${ }^{1}$ Although males are more exposed to urban violent events, Brazilian women are also exposed; when a traumatic event happens to women, they are more likely to develop PTSD. ${ }^{3}$ In the last 10 years,
Brazilian violence has increased and become epidemic in our country, derived from rises in inequality, greater availability of firearms, and increased drug consumption. ${ }^{49}$ This epidemic situation has increased exposure to traumatic events and caused an increase in PTSD risk, maintaining the relevance of our data.

Some methodological limitations of this work should be mentioned. Participants were recruited using a convenience sampling strategy, which could be a source of selection bias; our sample possibly exhibited more symptoms because they sought medical care at a program specifically designed for PTSD. Also, a healthy control group without trauma was not included in the design, although this could have enabled differentiation between the effects of trauma on individuals and the symptoms of PTSD. Finally, the present study did not find significant intergroup differences in the parental relationship questionnaires, probably because the sample size was insufficient to detect a difference on this scale $(n=20)$. This loss was due to the fact that questionnaires were not filled out completely. Still, we believe that the comparison is relevant even with this small sample to emphasize the issue for future studies.

\section{Conclusion}

Why do some victims of urban violence in Brazil develop PSTD and others do not? Our study indicates that factors promoting resilience are responsible for protecting the victims in this context. Personal values that give meaning to life and actively facing problems are psychological factors that improve resilience in Brazilian victims of urban violence. Also, having mature defense mechanisms is correlated with a lower risk of developing PTSD, whereas immature defense mechanisms and emotional or physical abuse in childhood are more associated with that disorder.

With respect to future endeavors, it is important to understand resilience as a process rather than as a character trait. Interventions to promote resilience can be developed through personal psychoeducation and psychotherapy, at the individual level, as well as in the family or community. Individually, self-confidence, selfesteem, self-efficacy, and self-control have been linked to the development of resilient capacity. Self-confidence is derived from a secure emotional support (family, friendship, religion), while self-esteem comes from autonomy, initiative, social appreciation, peer approval and identity; self-efficacy, in turn, is developed from an understanding of personal strengths and limitations. ${ }^{50,51}$ In the family, factors that shape resilience are a positive outlook, a spiritual sense, communication and agreement 
among its members, flexibility, family time, sharing fun and the existence of rules and routines. ${ }^{52}$ Improving these psychosocial factors may help ameliorate the negative effects of urban violence on mental health.

\section{Acknowledgments}

This research received financial support from Fundo de Incentivo à Pesquisa e Eventos - Hospital de Clínicas de Porto Alegre (FIPE-HCPA).

\section{Disclosure}

No conflicts of interest declared concerning the publication of this article.

\section{References}

1. Luz MP, Coutinho ES, Berger W, Mendlowicz MV, Vilete LM, Mello $M F$, et al. Conditional risk for posttraumatic stress disorder in an epidemiological study of a Brazilian urban population. J Psychiatr Res. 2016;72:51-7.

2. Cunningham RM, Carter PM, Ranney M, Zimmerman MA, Blow FC, Booth BM, et al. Violent reinjury and mortality among youth seeking emergency department care for assault-related injury: a 2-year prospective cohort study. JAMA Pediatr. 2015;169:63-70.

3. Ribeiro WS, Mari Jde J, Quintana MI, Dewey ME, Evans-Lacko S, Vilete LM, et al. The impact of epidemic violence on the prevalence of psychiatric disorders in Sao Paulo and Rio de Janeiro, Brazil. PLoS One. 2013;8:e63545.

4. Windle G, Bennett KM, Noyes J. A methodological review of resilience measurement scales. Health Qual Life Outcomes. 2011;9:8.

5. Charney DS. Psychobiological mechanisms of resilience and vulnerability: implications for successful adaptation to extreme stress. Am J Psychiatry. 2004;161:195-216.

6. Comasco E, Gustafsson PA, Sydsjö G, Agnafors S, Aho N, Svedin CG. Psychiatric symptoms in adolescents: FKBP5 genotype--early life adversity interaction effects. Eur Child Adolesc Psychiatry. 2015;24:1473-83.

7. Haglund ME, Nestadt PS, Cooper NS, Southwick SM, Charney DS. Psychobiological mechanisms of resilience: relevance to prevention and treatment of stress-related psychopathology. Dev Psychopathol. 2007;19:889-920.

8. Wingo AP, Fani N, Bradley B, Ressler KJ. Psychological resilience and neurocognitive performance in a traumatized community sample. Depress Anxiety. 2010;27:768-74.

9. Iacoviello BM, Charney DS. Psychosocial facets of resilience: implications for preventing posttrauma psychopathology, treating trauma survivors, and enhancing community resilience. Eur J Psychotraumatol. 2014;5:10.3402/ejpt.v5.23970.

10. Eisman $A B$, Stoddard SA, Heinze J, Caldwell $\mathrm{CH}$, Zimmerman MA. Depressive symptoms, social support, and violence exposure among urban youth: a longitudinal study of resilience. Dev Psychol. 2015;51:1307-16.

11. Price JP. Cognitive schemas, defence mechanisms and posttraumatic stress symptomatology. Psychol Psychother. 2007;80(Pt 3):343-53.

12. Eglinton R, Chung MC. The relationship between posttraumatic stress disorder, illness cognitions, defence styles, fatigue severity and psychological well-being in chronic fatigue syndrome. Psychiatry Res. 2011;188:245-52.

13. Jun JY, Lee YJ, Lee SH, Yoo SY, Song J, Kim SJ. Association between defense mechanisms and psychiatric symptoms in North Korean Refugees. Compr Psychiatry. 2015;56:179-87.
14. Wasserman GA, McReynolds LS. Contributors to traumatic exposure and posttraumatic stress disorder in juvenile justice youths. J Trauma Stress. 2011;24:422-9.

15. Leenarts LE, Vermeiren RR, van de Ven PM, Lodewijks HP, Doreleijers TA, Lindauer RJ. Relationships between interpersonal trauma, symptoms of posttraumatic stress disorder, and other mental health problems in girls in compulsory residential care. J Trauma Stress. 2013;26:526-9.

16. Löfving-Gupta S, Lindblad F, Stickley A, Schwab-Stone M, Ruchkin V. Community violence exposure and severe posttraumatic stress in suburban American youth: risk and protective factors. Soc Psychiatry Psychiatr Epidemiol. 2015;50:539-47.

17. Cutajar MC, Mullen PE, Ogloff JR, Thomas SD, Wells DL, Spataro J. Psychopathology in a large cohort of sexually abused children followed up to 43 years. Child Abuse Negl. 2010;34:813-22.

18. Bishop M, Rosenstein D, Bakelaar S, Seedat S. An analysis of early developmental trauma in social anxiety disorder and posttraumatic stress disorder. Ann Gen Psychiatry. 2014;13:16.

19. Meyers JL, Lowe SR, Eaton NR, Krueger R, Grant BF, Hasin D. Childhood maltreatment, 9/11 exposure, and latent dimensions of psychopathology: a test of stress sensitization. J Psychiatr Res. 2015;68:337-45.

20. Heim C, Nemeroff CB. Neurobiology of posttraumatic stress disorder. CNS Spectr. 2009;14:13-24

21. Lima AR, Mello MF, Andreoli SB, Fossaluza V, de Araújo CM, Jackowski AP, et al. The impact of healthy parenting as a protective factor for posttraumatic stress disorder in adulthood: a case-control study. PLoS One. 2014;9:e87117.

22. Dovran A, Winje D, Øverland S, Arefjord K, Hansen A, Waage L. Childhood maltreatment and adult mental health. Nord J Psychiatry. 2016;70:140-5.

23. Sheehan DV, Lecrubier Y, Sheehan KH, Amorim P, Janavs J, Weiller $\mathrm{E}$, et al. The mini-international neuropsychiatric interview (M. I. N. I.): the development and validation of a structured diagnostic psychiatric interview for DSM-IV and ICD-10. J Clin Psychiatry. 1998;59 Suppl 20:22-33.

24. American Psychiatry Association. Diagnostic and statistical manual of mental disorders. Washington, DC: American Psychiatry Association; 2000.

25. Gonçalves DM, Stein AT, Kapczinski F. Avaliação de desempenho do Self-Reporting Questionnaire como instrumento de rastreamento psiquiátrico: um estudo comparativo com o Structured Clinical Interview for DSM-IV-TR. Cad Saúde Pública. 2008;24:380-90.

26. Davidson JR, Book SW, Colket JT, Tupler LA, Roth S, David D, et al. Assessment of a new self-rating scale for post-traumatic stress disorder. Psychol Med. 1997;27:153-60.

27. Wagnild GM, Young HM. Development and psychometric evaluation of the Resilience Scale. J Nurs Meas. 1993;1:165-78.

28. Andrews G, Singh M, Bond M. The Defense Style Questionnaire. J Nerv Ment Dis. 1993;181:246-56.

29. Bernstein DP, Ahluvalia T, Pogge D, Handelsman L. Validity of the Childhood Trauma Questionnaire in an adolescent psychiatric population. J Am Acad Child Adolesc Psychiatry. 1997;36:340-8.

30. Parker $\mathrm{G}$, Tupling $\mathrm{H}$, Brown LB. A Parental Bonding Instrument. $\mathrm{Br}$ J Med Psychol. 1979;52:1-10.

31. Pesce RP, Assis SG, Avanci JQ, Santos NC, Malaquias JV, Carvalhaes R. Cross-cultural adaptation, reliability and validity of the Resilience Scale. Cad Saude Publica. 2005;21:436-48.

32. Blaya C, Kipper L, Heldt E, Isolan L, Ceitlin LH, Bond M, et al. Brazilian Portuguese version of the Defense Style Questionnaire (DSQ-40) for defense mechanisms measure: a preliminary study. Rev Bras Psiquiatr. 2004;26:255-8.

33. Grassi-Oliveira R, Stein LM, Pezzi JC. Translation and content validation of the Childhood Trauma Questionnaire into Portuguese language. Rev Saude Publica. 2006;40:249-55.

34. Kendler KS. Parenting: a genetic-epidemiologic perspective. Am J Psychiatry. 1996;153:11-20.

35. Cox BJ, Enns MW, Clara IP. The Parental Bonding Instrument: confirmatory evidence for a three-factor model in a psychiatric clinical sample and in the National Comorbidity Survey. Soc Psychiatry Psychiatr Epidemiol. 2000;35:353-7.

36. Terra L, Hauck S, Schestatsky S, Fillipon AP, Sanchez P, Hirakata $V$, et al. Confirmatory factor analysis of the Parental Bonding Instrument in a Brazilian female population. Aust N Z J Psychiatry. 2009;43:348-54.

37. Kessler RC, Rose S, Koenen KC, Karam EG, Stang PE, Stein DJ, et al. How well can post-traumatic stress disorder be predicted from pre-trauma risk factors? an exploratory study in the WHO World Mental Health Surveys. World Psychiatry. 2014;13:265-74. 
38. Haglund ME, Nestadt PS, Cooper NS, Southwick SM, Charney DS. Psychobiological mechanisms of resilience: relevance to prevention and treatment of stress-related psychopathology. Dev Psychopathol. 2007;19:889-920.

39. Feder A, Nestler EJ, Charney DS. Psychobiology and molecular genetics of resilience. Nat Rev Neurosci. 2009;10:446-57.

40. Hjemdal O, Roazzi A, Dias Mda G, Friborg O. The cross-cultural validity of the Resilience Scale for Adults: a comparison between Norway and Brazil. BMC Psychol. 2015;3:18.

41. Hauck S, Schestatsky S, Terra L, Knijnik L, Sanchez P, Ceitlin LHF. Adaptação transcultural para o português brasileiro do Parental Bonding Instrument (PBI). Rev Psiquiatr Rio Gd Sul. 2006;28:162-8.

42. Collishaw S, Pickles A, Messer J, Rutter M, Shearer C, Maughan B. Resilience to adult psychopathology following childhood maltreatment: evidence from a community sample. Child Abuse Negl. 2007;31:211-29.

43. Mehta $D$, Binder EB. Gene $\times$ environment vulnerability factors for PTSD: the HPA-axis. Neuropharmacology. 2012;62:654-62.

44. Lima AR, Mello MF, Andreoli SB, Fossaluza V, de Araújo CM, Jackowski AP, et al. The impact of healthy parenting as a protective factor for posttraumatic stress disorder in adulthood: a case-control study. PLoS One. 2014;9:e87117.

45. Grassi-Oliveira R, Stein LM. Childhood maltreatment associated with PTSD and emotional distress in low-income adults: the burden of neglect. Child Abuse Negl. 2008;32:1089-94.

46. Leenarts LE, Diehle J, Doreleijers TA, Jansma EP, Lindauer RJ. Evidence-based treatments for children with trauma-related psychopathology as a result of childhood maltreatment: a systematic review. Eur Child Adolesc Psychiatry. 2013;22:269-83.
47. Carrion VG, Wong SS. Can traumatic stress alter the brain? understanding the implications of early trauma on brain development and learning. J Adolesc Health. 2012;51(2 Suppl):S23-8.

48. Simeon D, Knutelska M, Yehuda R, Putnam F, Schmeidler J, Smith LM. Hypothalamic-pituitary-adrenal axis function in dissociative disorders, post-traumatic stress disorder, and healthy volunteers. Biol Psychiatry. 2007;61:966-73.

49. Murray J, Cerqueira DR, Kahn T. Crime and violence in Brazil: Systematic review of time trends, prevalence rates and risk factors. Aggress Violent Behav. 2013:471-483.

50. Shastri PC. Resilience: Building immunity in psychiatry. Indian J Psychiatry. 2013;55:224-34.

51. Thomas FC, Roberts B, Luitel NP, Upadhaya N, Tol WA. Resilience of refugees displaced in the developing world: a qualitative analysis of strengths and struggles of urban refugees in Nepal. Confl Health. 2011;5:20.

52. Cabanyes Truffino J. Resilience: An approach to the concept. Rev Psiquiatr Salud Ment. 2010;3:145-51.

\section{Correspondence:}

Stefania Pigatto Teche

Rua Ramiro Barcelos, 2350, Psiquiatria, Ala 40 Norte, Bairro Rio Branco

90035-903 - Porto Alegre, RS - Brazil

Tel.: +55 (51) 3359-8294

E-mail: stepigatto@gmail.com 